American Journal of Pharmaceutical Education 2020; 84 (11) Article 8025.

\title{
RESEARCH
}

\section{Placement and Integration of Pathophysiology, Anatomy, and Physiology Within the Doctor of Pharmacy Curriculum}

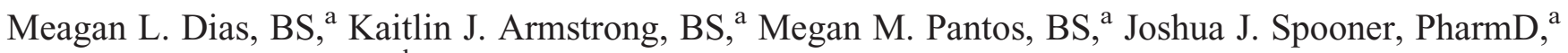 \\ Daniel R. Kennedy, $\mathrm{PhD}^{\mathrm{a}, \mathrm{b}}$ \\ ${ }^{a}$ Western New England University, College of Pharmacy and Health Sciences, Springfield, Massachusetts \\ ${ }^{\mathrm{b}}$ Editorial Board Member, American Journal of Pharmaceutical Education, Arlington, Virginia \\ Submitted February 14, 2020; accepted July 15, 2020; published November 2020.
}

\begin{abstract}
Objective. To examine the placement of pathophysiology, anatomy, and physiology within the curricula of US pharmacy schools and colleges for variations in program length, prerequisites, institution type, geographic region, and establishment date.

Methods. The websites of 146 pharmacy programs were examined for information related to pathophysiology, anatomy, and physiology courses and instruction. Eight programs listed uninterpretable or incomplete website data and were excluded, producing a final sample size of 138 programs. Data were analyzed to determine differences in curricular placement, credit hours, and integration.

Results. The majority $(65.3 \%)$ of pathophysiology courses were incorporated into the curriculum by integration, while some (14.5\%) had both stand-alone and integrated pathophysiology courses. The remaining programs $(20.2 \%)$ had stand-alone pathophysiology courses only. Of those with stand-alone pathophysiology courses, the mean number of credit hours was 5. Most programs (76.1\%) required anatomy and/or physiology as a prerequisite or as part of the professional program, with significantly more public programs than private programs requiring it as a prerequisite $(77.9 \%$ vs $48.6 \%)$.

Conclusion. Pathophysiology is taught in diverse formats throughout US pharmacy schools, with the only consensus among programs being that it belongs in the professional curriculum. While the majority of programs teach pathophysiology as an integrated course, stand-alone courses are also common. There is also great diversity in the type of instruction used in anatomy and physiology courses. While every program requires students to complete anatomy and physiology courses, these are commonly taught as part of the professional curriculum or are prerequisites. Overall, there are few significant differences in the instruction of these subjects among US pharmacy schools.
\end{abstract}

Keywords: anatomy, physiology, pathophysiology, pharmacy, curriculum

\section{INTRODUCTION}

There has been a continuous push by the pharmacy profession and pharmacy educators to expand the scope of pharmacy practice and introduce new roles for pharmacists on the healthcare team. Since the philosophy of pharmaceutical care was introduced in the 1990s by Hepler and Strand, ${ }^{1}$ there have been evolving standards of practice and education within pharmacy to broaden the clinical services offered. As the demands of the profession expand beyond the role of manufacturing and dispensing medications, pharmacists must develop a thorough knowledge base of pharmacotherapeutics to adapt. ${ }^{2}$ Studies

Corresponding Author: Daniel R. Kennedy, Western New England University, College of Pharmacy and Health Sciences, 1215 Wilbraham Rd., Springfield, MA 01119. Tel: 413-796-2413. E-mail: dkennedy@wne.edu have shown that including pharmacists on healthcare teams leads to better patient outcomes. ${ }^{3}$ As the field of pharmacy focuses more on the provision of clinical care, it is becoming increasingly imperative that pharmacy education and training include the appropriate basic science and clinical applications to prepare graduates who can assume clinical responsibilities.

Since the publication of the Flexner report, health education has focused on first teaching basic sciences and then developing clinical skills and reasoning. ${ }^{4}$ While the argument has since been made that practitioners rely more on encapsulated knowledge and recalling clinically relevant concepts rather than the underlying science and mechanisms, ${ }^{5,6}$ it remains true that an understanding of the underlying physiology and pathophysiology of a disease state leads to better retention and long term retrieval of knowledge and that this knowledge is heavily 


\section{American Journal of Pharmaceutical Education 2020; 84 (11) Article 8025.}

relied on when practitioners are faced with complex cases. ${ }^{7,8}$ As such, pathophysiology, anatomy, and physiology are essential components to pharmacy education and necessary precursors to pharmacists' understanding of pharmacotherapy and the development of clinical reasoning. ${ }^{9}$ This appears to be widely accepted across the Academy, with perhaps the most telling example being a popular textbook used to teach therapeutics in pharmacy curricula: Pharmacotherapy: A Pathophysiologic Approach. ${ }^{10}$

Despite the importance of pathophysiology and anatomy and physiology in pharmacy education, little literature examining these subjects exists. One study published in 2016 found that $62 \%$ of pharmacy programs required physiology as a prerequisite, and that $54 \%$ of programs offered a stand-alone physiology course in the professional program, while $46 \%$ integrated physiology with other course work (including pathophysiology, pharmacology, medicinal chemistry, or therapeutics). ${ }^{9}$ An earlier study published in 2009 found that $62 \%$ of pharmacy programs required anatomy and $54 \%$ of pharmacy programs required physiology before matriculation into a Doctor of Pharmacy (PharmD) program. ${ }^{11}$

With this in mind, the objective of this study was to examine the amount and placement of pathophysiology, anatomy, and physiology courses within pharmacy curricula, looking specifically at variations in program length, prerequisites, institution type, integration, and location in order to determine the level of consistency across pharmacy schools in the United States.

\section{METHODS}

A list of 146 pharmacy programs was compiled in December 2018 from the Accreditation Council for Pharmacy Education's (ACPE's) list of programs that were accredited, accredited with probation, or in candidate status. ${ }^{12}$ The ACPE website was used to determine the accreditation status and institution type (public or private) of each program. We examined the websites of these programs between December 2018 and February 2019, and collected the following information from electronically published course catalogs and curricula: length of program, anatomy and physiology requirements, and pathophysiology requirements. The primary source of information was published curricula. Course catalogs were used to clarify or supplement missing or ambiguous information and to determine whether pathophysiology was incorporated into integrated courses. Eight programs listed uninterpretable, incomplete, or out of date data on their website and were therefore excluded from the study, producing a final sample size of 138 programs. The curricular requirements for anatomy and physiology and pathophysiology were further categorized as follows: required as a prerequisite (defined as required for matriculation into the program), required in the professional program (defined as a component of the program's curriculum), both, or neither (not required at all). The number of credit hours for each anatomy and physiology course or pathophysiology course were also recorded.

Courses that were categorized as being part of the professional program were further defined as integrated, stand-alone, or both. Course descriptions published in electronic course catalogs available on the institution's website were used by the researchers to determine whether a course was integrated. The criteria used to make the determination that a course was stand-alone in structure was based on whether the words "pathophysiology" or "anatomy and physiology" or "physiology" appeared in the course title in the absence of the other content descriptors. Similarly, if the course included the words "pathophysiology" or "anatomy and physiology" along with other content areas, we determined that these subjects were integrated into the course.

Programs were defined as "emerging" or "legacy" based on their initial date of ACPE accreditation (with programs enrolling their first class prior to 2000 categorized as legacy and programs enrolling their first class in 2000 or later categorized as emerging). These time points were chosen because the Bachelor of Science in Pharmacy degree was no longer available to students enrolling after July $2000 .^{12,13}$ Programs were identified as being either a three-year or four- year program based on the curriculum posted on the program's website. Programs with multiple campuses were examined individually to determine whether the campuses had unique curricula; there were five programs in which a branch program was considered a separate program from the main campus either because of differences in total program length $(n=4)$ or differences in candidate status $(n=1)$. Four programs were excluded from the subanalysis of threeyear programs vs four-year programs because they described themselves as being six-year programs and did not have a clear point where the students transitioned from the undergraduate to the graduate curriculum. For this reason, we did not assume that the last four years of the six-year program were similar in format to a four-year program (although this was likely true).

Data were examined for potential differences based on common program demographics, including program length, institution type, geographic region (Northeast, Southeast, Midwest, West, and Southwest, as defined by the National Geographic Society ${ }^{14}$ ), and establishment date. Categorical and continuous data were analyzed using the Fisher exact test and $t$ tests, respectively, using 


\section{American Journal of Pharmaceutical Education 2020; 84 (11) Article 8025.}

Prism8 (GraphPad Software, LLC; San Diego, CA). Nonparametric geographic region data were analyzed using a Spearman rank test and Kendall rank coefficient, calculated using SPSS statistical software (IBM, Armonk, NY).

\section{RESULTS}

Summaries and comparisons of requirements for pathophysiology instruction are displayed in Table 1 and methods of course instruction are described in Table 2. Private schools were significantly more likely than public schools to require students to complete a pathophysiology course within the professional program $(95.7 \%$ vs $83.8 \%$ $p=.025)$. There were no significant differences between three-year and four-year programs for pathophysiology requirements or course type; however, three-year programs, on average, required more stand-alone pathophysiology credits than four-year programs (6.0 vs 4.8), and private programs, on average, required more standalone pathophysiology credits than public programs (5.4 vs 4.5 ) (Table 1). Furthermore, almost $90 \%$ of programs $(124 / 138)$ had pathophysiology in their curriculum, but no program had it as a prerequisite. Of the programs in which pathophysiology instruction could be identified, the majority $(65.3 \%)$ required instruction in pathophysiology only as part of an integrated course or course series, with fewer programs requiring a stand-alone pathophysiology course $(20.2 \%)$ or both stand-alone and integrated courses in pathophysiology (14.5\%).

The breakdown of credit hours for stand-alone pathophysiology courses in the professional program is presented in Table 3. For the schools that solely offered stand-alone pathophysiology courses $(\mathrm{N}=25)$, two had two credit hours of stand-alone instruction in pathophysiology, five schools had 3 credit hours, one school had 3.5 credit hours, seven schools had 4 credit hours, two schools had 5 credit hours, five schools have 6 credit hours, two had 8 credit hours, and one had 9 credit hours. There were no differences between emerging and legacy programs in the offering of pathophysiology or the type of pathophysiology course(s) offered nor significant regional differences between placement of pathophysiology in the curriculum or type of course (integrated only, stand-alone only, or both).

The breakdown of instruction in anatomy and physiology between the required professional curriculum and prerequisites is shown in Table 4, and whether the courses are integrated or stand-alone is shown in Table 5. Briefly, $100 \%$ of programs required that students have instruction in anatomy and physiology, the majority $(63.0 \%)$ required this only as a prerequisite, $24.0 \%$ only as a component of the professional curriculum, and $13.0 \%$ as both a prerequisite and in the required curriculum. Furthermore, of the 51 programs that required instruction in anatomy and physiology in the professional program, the majority $(62.8 \%, n=32)$ required students to complete a stand-alone course or courses, while the remaining programs $(37.3 \%, \mathrm{n}=19)$ integrated anatomy and physiology into other coursework. We found that anatomy and physiology was incorporated into the curriculum in several different ways, including anatomy only components, physiology only components, and both anatomy and physiology as stand-alone or integrated courses.

Regarding institution type, more public schools than private schools required anatomy and physiology as a prerequisite $(88.2 \%$ vs $64.3 \% p=.001)$. In addition, more private schools than public schools required it in the professional program $(51.4 \%$ vs $22.1 \% p<.001$, while some programs required it in both (Table 4). In general, programs that included anatomy and physiology in their professional program favored having it as a stand-alone course $(62.8 \%)$ rather than as part of an integrated course $(37.3 \%)$, with no significant differences found in program length or institution type.

There were no significant differences between legacy and emerging programs regarding either the placement of anatomy and physiology within their program, or whether it was integrated or stand-alone. Furthermore, there were no regional differences regarding placement of anatomy and physiology as a prerequisite or required course or, if a required course, whether it was integrated, stand-alone, or both.

Table 1. Pathophysiology Content in the Doctor of Pharmacy Curriculum of US Schools and Colleges of Pharmacy

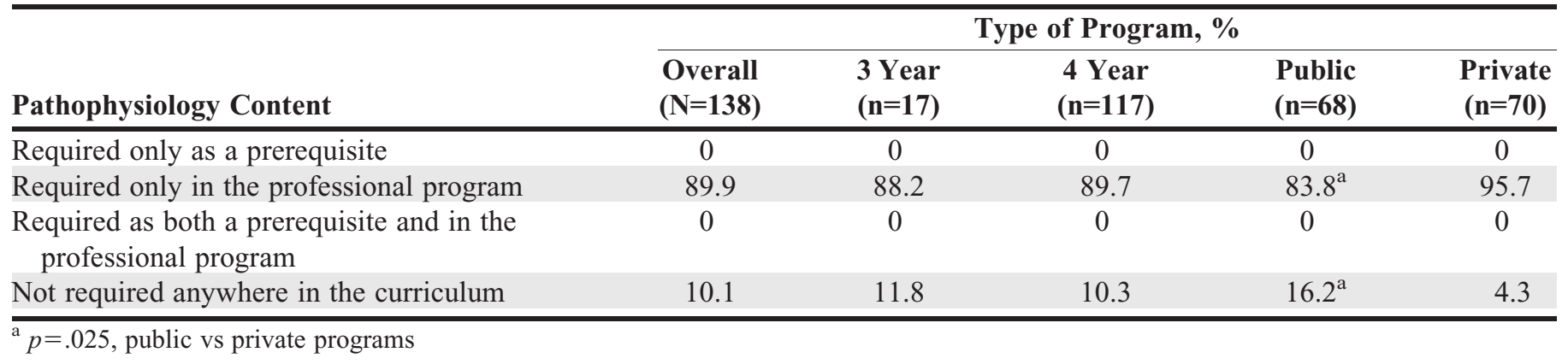




\section{American Journal of Pharmaceutical Education 2020; 84 (11) Article 8025.}

Table 2. Integrated Pathophysiology Content in the Professional Curriculum of US Schools and Colleges of Pharmacy

\begin{tabular}{|c|c|c|c|c|c|}
\hline & \multicolumn{5}{|c|}{ Type of Program, \% } \\
\hline & $\begin{array}{l}\text { Overall } \\
(\mathrm{N}=124)\end{array}$ & $\begin{array}{l}3 \text { year } \\
(n=15)\end{array}$ & $\begin{array}{c}4 \text { year } \\
(n=105)\end{array}$ & $\begin{array}{l}\text { Public } \\
(n=57)\end{array}$ & $\begin{array}{c}\text { Private } \\
(n=67)\end{array}$ \\
\hline Required as a stand-alone course & 34.7 & 33.3 & 35.2 & 38.8 & 31.3 \\
\hline Required only in integrated courses & 65.3 & 66.7 & 64.8 & 61.4 & 68.7 \\
\hline Required only in stand-alone courses & 20.2 & 20.0 & 20.0 & 21.2 & 19.4 \\
\hline
\end{tabular}

\section{DISCUSSION}

As the scope of pharmacy practice expands and new roles for pharmacists within the healthcare team emerge, adequate placement of key biological sciences is crucial in pharmacy education. In this work, the amount and placement of anatomy, physiology, and pathophysiology within pharmacy curricula were explored based on program length, prerequisites, and institution type across US schools and colleges of pharmacy. These disciplines were found to be incorporated into pharmacy curricula in a variety of ways including as stand-alone courses, part of integrated courses, or both.

In pharmacy programs in the United States, pathophysiology and the related disciplines of anatomy and physiology are incorporated into curricula in a variety of ways, including as stand-alone courses, part of integrated courses, or as prerequisite courses. As curricular integration has been of particular interest recently in both pharmacy and medical education, ${ }^{15,16}$ the differences in delivery between integrated and nonintegrated delivery of these courses was interesting, especially as some programs had both stand-alone and integrated courses. In general, recent trends in pharmacy curricula reform have focused on curricula being more outcomes focused and patient-centered, sometimes at the expense of the basic pharmaceutical sciences. ${ }^{17}$ As pharmacy curricula change, prerequisites for these programs is also of interest, as the courses required vary across PharmD programs. In a study by Boyce and Lawson in 2009 evaluating the prerequisite requirements in the domains of anatomy and physiology, out of 71 programs, $62 \%(n=44)$ of programs required students to complete an anatomy course and 54\% $(n=38)$ of programs required students to complete a physiology course before matriculation into the PharmD program. ${ }^{11}$ The number of PharmD programs has increased significantly since the Boyce study, and we observed a noticeable increase over the past decade in the number of schools $(76.1 \%, \mathrm{n}=105)$ that require both anatomy and physiology as prerequisites. Additionally, the Boyce study focused solely on preprofessional coursework required for entry into PharmD programs without exploring the degree to which these areas of study were incorporated into the PharmD curriculum itself. This study observed all programs requiring anatomy and

Table 3. Credit Hours Assigned to Stand-alone Pathophysiology Courses in US Doctor of Pharmacy Programs

\begin{tabular}{lcc}
\hline Type of Program & Mean Credit Hours (SD) & Range of Credit Hours \\
\hline Structure & & \\
$\quad$ Three year $(\mathrm{n}=5)$ & $6.0(2.3)$ & $3-9$ \\
Four year $(\mathrm{n}=37)$ & $4.8(1.8)$ & $2-8$ \\
Public programs $(\mathrm{n}=22)$ & $4.5(1.8)$ & $2-8$ \\
Private programs $(\mathrm{n}=21)$ & $5.4(1.8)$ & $3-9$ \\
Location & & $3-8$ \\
$\quad$ Northeast $(\mathrm{n}=9)$ & $6.0(2.2)$ & $2-9$ \\
Southeast $(\mathrm{n}=16)$ & $4.9(1.7)$ & $2-8$ \\
Southwest $(\mathrm{n}=4)$ & $5.0(2.6)$ & $3-7$ \\
Midwest $(\mathrm{n}=9)$ & $4.3(1.3)$ & $3-8$ \\
West $(\mathrm{n}=3)$ & $5.0(2.7)$ & $3-3.5$ \\
Other $(\mathrm{n}=2)$ & $3.3(0.4)$ & $2-9$ \\
Date of Establishment & & $2-8$ \\
Legacy $(\mathrm{n}=31)$ & $5.1(1.9)$ & 2.5 \\
Emerging $(\mathrm{n}=12)$ & $4.5(1.9)$ & \\
\hline
\end{tabular}




\section{American Journal of Pharmaceutical Education 2020; 84 (11) Article 8025.}

Table 4. Placement of Anatomy and Physiology Courses in the Doctor of Pharmacy Curriculum by US Schools and Colleges of Pharmacy

\begin{tabular}{|c|c|c|c|c|c|}
\hline & \multicolumn{5}{|c|}{ Type of Program, \% } \\
\hline & $\begin{array}{l}\text { Overall } \\
(\mathrm{N}=138)\end{array}$ & $\begin{array}{l}3 \text { Year } \\
(n=17)\end{array}$ & $\begin{array}{l}4 \text { Year } \\
(n=117)\end{array}$ & $\begin{array}{l}\text { Public } \\
(\mathrm{n}=68)\end{array}$ & $\begin{array}{c}\text { Private } \\
(n=70)\end{array}$ \\
\hline Required only as a prerequisite & 63.0 & 58.8 & 65.8 & $77.9^{\mathrm{a}}$ & 48.6 \\
\hline Required only in the professional program & 23.9 & 17.7 & 22.2 & $11.8^{\mathrm{b}}$ & 35.7 \\
\hline $\begin{array}{l}\text { Required as both a prerequisite and in the } \\
\text { professional program }\end{array}$ & 13.0 & 23.5 & 12.0 & 10.3 & 15.7 \\
\hline Not required anywhere in the curriculum & 0 & 0 & 0 & 0 & 0 \\
\hline
\end{tabular}

${ }^{\mathrm{a}} p=.0004$ vs. private programs

${ }^{\mathrm{b}} p=.0013$ vs. private programs

physiology to some degree and added how colleges incorporate anatomy and physiology into the professional program if they are not perquisite courses.

We found that private schools were more likely to require pathophysiology in the professional program compared to public schools. We postulated that perhaps public programs include more coursework in anatomy and physiology than private programs during the professional curriculum, but the data did not support this. Also, some programs required study of anatomy and physiology as both a prerequisite and in the professional program. Most of these programs incorporated anatomy and physiology into the professional program through integration of subject matter in these areas with subject matter in related disciplines, or had an anatomy course as a prerequisite and a physiology course included in the professional program.

We postulated that three-year programs may require anatomy and physiology courses as a prerequisite to a greater extent than four-year programs to compensate for the acceleration of the curriculum. Additionally, we expected that three-year programs would also have more integrated pathophysiology courses compared to fouryear programs for the same reason. However, no significant differences in these metrics were noted between three- and four-year programs.
There are some limitations to this study. First, the collection of data through pharmacy program websites may have limited sample size, as eight programs had uninterpretable or incomplete website data. In addition, 14 programs did not list pathophysiology in their course descriptions, which could lead to underrepresentation if this was not an accurate reflection of their curriculum due to course descriptions that omitted the word. In our experience, ${ }^{18,19}$ conducting a survey would not have resulted in data that were as robust as that gleaned from program websites because of the possibility of a poor survey response rate. Despite that we had to exclude eight programs and that 14 programs may have resulted in underrepresentation, a poor survey response rate would have been more likely to skew our data by not providing an adequate number of programs to analyze. Similarly, the methodology for categorizing courses as stand-alone or integrated is not explicitly established, so the methods used in this work may differ from those used in other research. However, these methods fit within the definition of integrated education provided by Pearson and Hubball that "integration strategies involve sequential scheduling of related disciplines," ${ }^{20}$ such as pathophysiology content followed by pharmacology and therapeutics. Additionally, we could not determine the quantity of pathophysiology taught in each integrated course, so we could not

Table 5. Breakdown in Stand-alone vs Integrated Anatomy and Physiology Courses in the Professional Curriculum of US Schools and Colleges of Pharmacy

\begin{tabular}{|c|c|c|c|c|c|}
\hline & \multicolumn{5}{|c|}{ Type of Program, \% } \\
\hline & $\begin{array}{l}\text { Overall } \\
(\mathrm{N}=51)\end{array}$ & $\begin{array}{l}3 \text { year } \\
(n=7)\end{array}$ & $\begin{array}{l}4 \text { year } \\
(n=40)\end{array}$ & $\begin{array}{l}\text { Public } \\
(n=15)\end{array}$ & $\begin{array}{c}\text { Private } \\
(n=36)\end{array}$ \\
\hline $\begin{array}{l}\text { Required in the professional program as only } \\
\text { stand-alone courses }\end{array}$ & 62.8 & 42.9 & 62.5 & 73.3 & 58.3 \\
\hline
\end{tabular}




\section{American Journal of Pharmaceutical Education 2020; 84 (11) Article 8025.}

compare integrated courses using credit hours as we did with stand-alone courses. However, it is our experience with integrated courses that it is difficult if not impossible to accurately break out the amount of time spent on a distinct subject like pathophysiology from therapeutics as these topics are often covered in the same lectures.

The most unexpected finding from this study was that $14(10.1 \%)$ US pharmacy programs did not require pathophysiology anywhere in their curriculum. However, it is unlikely that most of these programs do not require pathophysiology. Rather, instruction in pathophysiology at these schools is probably incorporated into another subject such as biomedical sciences or pharmaceutical sciences. The ACPE has stated that the biomedical sciences, including pathophysiology, may be addressed in the preprofessional curriculum and is not a required element of the didactic portion of the curriculum, ${ }^{12}$ but we found no program that required completion of a pathophysiology course as an entry requirement for the professional program.

As the landscape of pharmacy education has changed, new trends have emerged. The majority of new pharmacy programs are at private colleges, and the number of programs offering accelerated, three-year PharmD programs has increased. ${ }^{21}$ With such rapid growth and expansion of the educational institutions supplying pharmacists to the profession, and concerns about whether the quality of education is being maintained, ${ }^{22}$ the Academy must consider whether the placement of and amount of contact time dedicated to teaching key biological and pharmaceutical sciences is adequate to support a modern pharmacists' clinical education.

\section{CONCLUSION}

Within the curricula of US pharmacy schools, we found pathophysiology taught in various formats, but commonly integrated within other courses. Anatomy and physiology was mainly seen within pharmacy curricula as a stand-alone course. Private schools were significantly more likely than public schools to require pathophysiology within the professional program. Anatomy and physiology courses were prerequisites for most pharmacy curricula, with public programs more likely to require it as a prerequisite. Few schools (mainly private programs) had integrated anatomy and physiology into their professional curriculum. Overall, few significant differences in the amount of pathophysiology, anatomy, and physiology content taught within the PharmD curricula were found, regardless of the differences in program length, institution type, and geographical region.

\section{REFERENCES}

1. Hepler CD, Strand LM. Opportunities and responsibilities in pharmaceutical care. Am J Hosp Pharm. 1990;47(3):533-543.

2. Wright DFB, Anakin MG, Duffull SB. Clinical decision-making: An essential skill for 21 st century pharmacy practice. Res Social Adm Pharm. 2019;15(5):600-606.

3. Chisholm-Burns MA, Kim Lee J, Spivey CA, et al. US pharmacists' effect as team members on patient care: systematic review and meta-analyses. Med Care. 2010;48(10):923-933. 4. Flexner A. Medical education in the United States and Canada. From the Carnegie Foundation for the Advancement of Teaching, Bulletin Number Four, 1910. Bull World Health Organ. 2002;80(7):594-602.

5. Ahopelto I, Mikkila-Erdmann M, Olkinuora E, Kaapa P. A followup study of medical students' biomedical understanding and clinical reasoning concerning the cardiovascular system. Adv Health Sci Educ Theory Pract. 2011;16(5):655-668.

6. Rikers RM, Schmidt HG, Boshuizen HP. Knowledge encapsulation and the intermediate effect. Contemp Educ Psychol. 2000;25(2):150-166. 7. Woods NN, Brooks LR, Norman GR. The role of biomedical knowledge in diagnosis of difficult clinical cases. Adv Health Sci Educ Theory Pract. 2007;12(4):417-426.

8. Woods NN, Neville AJ, Levinson AJ, Howey EH, Oczkowski WJ, Norman GR. The value of basic science in clinical diagnosis. Acad Med. 2006;81(10 Suppl):S124-127.

9. Islam MA, Khan SA, Talukder RM. Status of physiology education in US Doctor of Pharmacy programs. Adv Physiol Educ. 2016;40(4):501-508.

10. DiPiro JT, Posey L, Haines ST, Nolin TD, Ellingrod V. Pharmacotherapy: A Pathophysiologic Approach. Vol 11. New York, NY: McGraw-Hill; 2020.

11. Boyce EG, Lawson LA. Preprofessional curriculum in preparation for doctor of pharmacy educational programs. Am J Pharm Educ. 2009;73(8):155.

12. ACPE. PharmD Program Accreditation. https://www.acpeaccredit.org/pharmd-program-accreditation/. Accessed October 29, 2020 13. Vuernick EL, Josefiak KF, Spooner JJ, Kennedy D. Non-terminal degree offerings in US pharmacy programs. Am J Pharm Educ. 2019; 83(7): Article 6917.

14. United States Regions. National Geographic Society. www.nationalgeographic.org/maps/united-states-regions. Accessed October 29, 2020.

15. Pearson ML, Hubball HT. Curricular integration in pharmacy education. Am J Pharm Educ. 2012;76(10):204.

16. Quintero GA, Vergel J, Arredondo M, Ariza MC, Gomez P, Pinzon-Barrios AM. Integrated medical curriculum: advantages and disadvantages. J Med Educ Curric Dev. 2016;3.

17. Woster PM. Maintaining basic science content throughout the PharmD curriculum. Am J Pharm Educ. 2003;67(3):99.

18. Kennedy DR, Ginsburg DB, Harnois NJ, Spooner JJ. The role and responsibilities of pharmacy student government associations in pharmacy programs. Am J Pharm Educ. 2015;79(7):100.

19. Galinski CN, Horosz PJ, Spooner JJ, Kennedy DR. Comparison of introductory pharmacy practice experiences among US pharmacy programs. Am J Pharm Educ. 2014;78(9):162.

20. Pearson ML, Hubball HT. Curricular integration in pharmacy education. Am J Pharm Educ. 2012;76(10):204.

21. Knapp DA, Knapp DE. Attributes of colleges and schools of pharmacy in the United States. Am J Pharm Educ. 2009;73(5):96. 22. Mattingly TJ, Romanelli F, Cain J, Schlesselman LS. Measuring up - defining the quality of PharmD programs. Am J Pharm Educ. 2017;81(9):6071. 